ISSN: 2162-3104 Print/ ISSN: 2166-3750 Online

Volume 7, Issue 2 (2017), pp. 347-466

(C) Journal of International Students

http://jistudents.org/

\title{
Digital Journeys: A Perspective on Understanding the Digital Experiences of International Students
}

\author{
Shanton Chang, The University of Melbourne, Australia \\ Catherine Gomes, RMIT University, Australia
}

\begin{abstract}
The authors in this conceptual paper draw on the literature on information seeking behavior, social media use, and international student experiences to propose Digital Journeys as a framework which helps us understand the online behavior of international students. Here we theorize that the Digital Journey is the transition that individuals make online from relying on one digital bundle of information sources to a new bundle. This "new" digital bundle possibly can base in the new host country or internationally. We furthermore suggest that Digital Journeys is not only an under investigated phenomenon but a thoroughly necessary space to examine in order to improve the ways in which we present information to international students.
\end{abstract}

Keywords: digital journey, digital environment, information-seeking behavior, social media

In the Asia-Pacific region, the most popular destination for Asian, African or Latin-American international students is Australia (Gomes, in press). There were, in the 2014-2015 academic year 525,172 international students, including exchange students (Australian Department of Education and Training, 2015). With the increase in volume and diversity of students, many education providers seem to be turning to the digital space as a way of communicating more efficiently with students.

Communicating with international students has been in focus for international education providers. Whether providing marketing information for potential new students or parents, providing support information for wellbeing, or communicating across cultures within and beyond the classroom, Australian educational institutions have to grapple with the challenges involved in providing timely and relevant information to 
international students. The major International Education Conferences of the world, , have been focusing on themes related to digital communication for the last 10 years. For example, the following indicative list highlighted that the use of digital technology has been of great interest to practitioners of international education. ISANA International Education Association Conference's 2011 theme was "Innovations in Working with Diverse Students”, NAFSA: Association of International Educators' 2011 Conference theme was "Innovation and Sustainability in International Education", the European Association of International Education (EAIE) Conference's 2014 theme was "Stepping into a new era", the Australian International Education Conference's (AIEC) 2016 theme was "Connectivity - at the health of international education", and the Australia New Zealand Student Services Association (ANZSSA) Conference's 2016 theme was "Inspire, Innovate, Involve: Insights into new horizons for student experience \& engagement”. The wide-ranging applications of digital technology as a platform for communication and innovation in international education continue to be of interest to education providers.

Despite the increasing practice of putting more information online, there hasn't been a correlated increase in the study of how effective these practices might be in the literature. For example, Saw, Abbott, Donaghev, and McDonald (2013) pointed to the lack of understanding about how international students are actually using online sources for information. More importantly, ensuring that international student access and use the information they are provided within a timely manner is not welldocumented (Chang, Alzougool, Berry, Gomes, Smith \& Reeders, 2012). Much of this crucial information is now provided online (Mikal, Yang \& Lewis, 2015) as many institutions use the Internet to communicate with students, especially for international students. Although there is evidence that closely guided use of digital resources has been beneficial for international students within the classroom and curriculum (Abrahamse, Johnson, Levinson, Medsker, Pearce, Quiroga, \& Scipione, 2015; Cowling \& Novak, 2012; Shao \& Crook, 2015), there is lack of evidence that international students are necessarily well-informed on non-curricular matters as more and more information is moved online.

Previous studies have shown that due to the differences in the prior experiences of international and domestic students, their adjustment to their new tertiary institutions can vary (Bista \& Foster, 2016; HechanovaAlampay, Beehr, Christiansen, \& Van Horn, 2002; Khawaja \& Dempsey, 2008,). Due to international students having different educational backgrounds, cultural values, and expectations, they may sometimes experience more difficulties in transition to a new environment than domestic students. In addition, international students often experience higher level of home-sickness than domestic students, and great social 
isolation in their new host countries (Poyrazli \& Lopez, 2007). There are well-documented reports in the literature on the challenges for international students' initial transition to their host country but there is little research on international students' online experiences.

Binsahl, Chang, and Bosua (2015) reported that much of the research on the information seeking behavior of new international students have focused on academic information rather than coping with daily life (Sin \& Kim, 2013). Given the challenges outlined previously, such information is crucial for new international students' wellbeing particularly when it comes to them coping with the transition to a new cultural and educational environment. Even before the age of social media, Song (2004) pointed that it is crucial to understand the information seeking behavior of international students in order to communicate with them in an efficient way.

Esfahani and Chang (2012) and Song (2004) found that there are good reasons why international students seek out information differently when compared with domestic students. Song (2004) demonstrated that international students are more likely to go back to generic sources of information (e.g. Google or Yahoo!) they are familiar with, whereas domestic students are able to use educational institutions' library databases. In addition, Esfahani \& Chang (2012) highlighted that these differences in information seeking behavior might exist because of different level of intercultural adaptation, English proficiency, and digital literacy that differentiate between international and domestic students. Esfahani \& Chang (2012) suggested an initial conceptual model to understand the information seeking behavior of international students. They proposed several factors that impact on an international student's information seeking behavior, including external context (e.g. available resources and time constraints), cognitive (e.g. satisficing behavior) and internal (e.g. skill levels and intercultural adaptation) factors. However, while the work here provided a snapshot in time, they do not indicate what might happen over time.

Social media also plays a vital role as a source of information for international students. There is evidence that international students use various forms of social media and rely on a range of sources for information that is different from domestic students, ranging from different news sources and social media platforms such as Facebook, Qzone, Orkut, Mixi and Zing (Gomes, Berry, Alzougool \& Chang, 2015; Sandel, 2014). While many of these studies have indicated the benefits of social media in helping students make connections in new and sometimes isolating environments, others mentioned that there was a few potential barriers this medium can create for interaction with domestic students (Hodis \& Hodis 2012; Lee, Lee \& Jang, 2011; Olding, 2013). The interaction between international and domestic students has been considered an important aspect of international education 
by a number of authors, pointing to the benefits to students' social acculturation, personal development, and global competencies (Arkoudis, Yu, Baik, Chang, Lang, Lang, Pearce, \& Watty, 2010; Hechanova-Alampay et al., 2002; Leask, 2009).

Therefore, as more institutions (and governments) seek to put information online, either on websites or through their social media channels, there is a need to understand how international students might actually be accessing, or of more concern, not accessing crucial information. This accessing and not accessing of information is particularly important as many governments and institutions that recognize the roles of international students try to provide better services and information within their borders. Such information ranges from work rights, health, accommodation, news, entertainment, and banking (Binsahl \& Chang 2013). However, while some countries and institutions have had reasonable success in connecting with their international students through face-to-face networks, the provision of online information has been less successful (Chang et al., 2012).Therefore, the guiding question for this paper is:

How might we understand the online experiences and information seeking behaviors of international students as they move between countries?

This paper sought to answer the question by proposing a conceptual model for understanding the digital experiences of international students by looking at what international students do online when they move to a new country. It drew on existing literature on information seeking behavior, international students' online behavior, and social media use, including previous studies on international students' social networks. According to Moody (2005), this approach can be placed in the Synthesis (analytical) category because existing research findings will be synthesized into a unified conceptual framework. We adopted this methodology to bring together inter-disciplinary literature to understand the phenomenon from a wide perspective.

\section{BACKGROUND}

More recently, the experiences of international students have been supported by the Internet and social media which enable them to use sources of information they are familiar with as well as keep in touch with their friends from home (Chang et al., 2012; Gomes, 2014). Previous studies indicated that international students in Australia use social media to maintain social networks in order to create a space away from home for themselves in addition to the friends they make while in sojourn (Gomes et al., 2014). The dual experience of being physically in a foreign country but digitally connected to home country has been termed 'translocal' by Martin \& Rizvi (2014). 
Translocal refers to "the transplanting of the home nation experience overseas” (Martin \& Rizvi 2014, p. 1023-1024). Martin and Rizvi investigated how social media allows the international students who live in Melbourne to connect with the home nations through their active and daily use of non-English platforms (e.g. Weibo). Furthermore, they found that verbally and visually communicating with family and friends in real time through platforms such as Skype inadvertently leads to a fractured and somewhat different engagement in their host city of Melbourne. This disjuncture in the transient overseas experience may be a condition of time. In Wong's (2014) exploration of international students in Australia, he provided an example of a respondent who used to have daily 'live' Skype sessions with her family back in the home nation. These sessions took place when she had her dinners so that the family could virtually have their meals together. The respondent who was in her fourth year of study at the time of Wong's fieldwork, clarified that this was her routine only during her first year in Australia. However, Qiu, Lin \& Leung (2013) also suggested that this state of translocality might also present opportunities for cross-cultural comparison and negotiation, not to be seen as a deficit. However, translocality is not a constant state. It may change over time due to the nature of online behavior as people move across different websites and social networks.

Therefore, we drew on the literature on online information seeking behavior and online social networks to understand how international students might experience the Internet. In addition, there are a lot of practitioner research that looks at what are the most popular sites, sources of information and social networks in different countries and cultures (e.g., kpcb.com, pewinternet.org, digitaltrends.com, and domo.com). China, in particular, has completely different sets of social media and internet forums (chinainternetwatch, 2016). In summary, although, other than China, much of the world has access to similar internet sites and social media, netizens are using these forums and platforms differently. For example, Na, Kosinski \& Stillwell (2015) found that cultural values can determine the nature and construction of the online social networks and communities. This unsurprisingly suggested that even where the same social networking platforms are used, there is clearly a plethora of different online communities that may never interact with each other, for a range of reasons such as culture and country of origin. There is thus an urgent need to understand the complexity of online behaviour of international students in more depth.

\section{Understanding the Internet and Borders}

The Internet, especially in the developed Western world, is a relatively borderless space where netizens can quite easily cross over into 
new websites and apps. In short, the Internet is a space where people can choose what they access and behave in way they are familiar with. However, although there are strictly speaking no borders on the Internet, most netizens keep going to the same websites and apps for information. Moreover, netizens rely on a limited number of results from online search. It is due in part to the nature of web browsing.

Although there are millions of websites around the world, the majority exist in obscurity because most netizens tend to use the ones they are familiar with. For instance, web browsing was dominated by popular search engines such as Google, Baidu, Yahoo! and Bing (NetMarketShare, 2016). In the early study on mobile searches, Church, Smyth, Bradley and Cotter (2008) pointed out that netizens focus on top listed results when doing online search despite there are tons of results available offered to them. In the social networking space, researchers and practitioners are working at building recommendation systems that sift through the Internet for much relevant information based on pre-determined algorithms (Freyne, Berkovsky, Daly, \& Geyer, 2010). This creates an online environment --unless the certain website is remembered by netizens, it is unlikely to be searched. Therefore, despite the lack of borders online, netizens do not always cross them in order to go beyond what they are familiar with.

\section{Profiles of International Students as Information Seekers}

Moving away from the information provider, it is also important to look at the nature of the information seeker, in this case, the international students. In their study on health information seeking, Alzougool, Chang \& Gray (2013), showed that the information needs of the seeker is an important determinant of what they might search for online rather than what the information provider wants them to look for. They also showed that information needs are not always clearly defined even by individuals themselves. Alzougool et al.'s (2013) information needs model labels four descriptors in a matrix: demanded, undemanded, recognized and unrecognized information needs (See Figure 1). This model has been used in informing the design of websites and social media strategies in public health.

The model suggests that an individual might have recognized information needs, which are the self-identified needs amongst individuals. In the case of international students, this might occur when they recognize a need for some information when they are in the host country. The model also suggests that an individual might not even be aware of a particular unrecognized information need. In the context of international students, this might occur when they do not realize they need particular information because of their new environment. 
Figure 1. A Framework of States of Information Needs (Adapted from Alzougool, Chang and Gary, 2013)

\begin{tabular}{|l|l|l|}
\hline & Demanded & \multicolumn{1}{l}{ Undemanded } \\
\hline Recognized & $\begin{array}{l}\text { Recognized } \\
\text { Demanded }\end{array}$ & $\begin{array}{l}\text { Recognized } \\
\text { Undemanded }\end{array}$ \\
\hline Unrecognized & $\begin{array}{l}\text { Unrecognized } \\
\text { Demanded }\end{array}$ & $\begin{array}{l}\text { Unrecognized } \\
\text { Undemanded }\end{array}$ \\
\hline
\end{tabular}

A student who is actively seeking out information is shown to have demanded this information. Conversely, there may be students who choose to refuse or avoid information which can be seen as undemanded needs.

Therefore, there are four possible information needs amongst international students. Students who actively seek out information they think they need fall into the recognized demanded group. This would represent the context where students actually seek out information on their own. However, it is also possible to have recognized undemanded needs such as when international students who might be aware of their failing health but choose to ignore it, believing that they will get better, and thus will fail to seek out help or information. In addition, an international student in the unrecognized demanded category might not be aware of what exactly they should be looking for but could still display exploratory behaviors in their new environment and thus be open to new information. On the other hand, other students might not search out the information in an uncertain environment, falling into the unrecognized undemanded category.

The model suggests that individuals can move between the four categories given the context they find themselves in. In addition, Alzougool et al. (2013) argued that many websites are designed to disseminate information with the assumption that users recognize their lack of information and will actively seek it out. Therefore, they argued that many information providers only address the needs of the individuals who fall in the recognized demanded category. This model highlights that international students have diverse information needs. It also implies that an information provision strategy that relies on international students recognizing a need in the first place, and then actually seeking it out on their own in every instance they need information, is flawed.

In addition, as indicated earlier, even when international students do seek out information online, they do tend to rely on tried and tested sources. Alzougool, Chang, Gomes \& Berry (2013) found that due to accessibility, international students can continue to rely on home country sources for online information. If students are able to find the information they are 
looking for in 'home sources', they are likely to be satisfied with that despite any perceived risk of relevance or reliability. This is called 'satisficing behavior' where students 'justify a conservative information strategy, retaining established strategies as far as possible and completing tasks with minimum information-seeking effort' (Warwick, Rimmer, Blandford, Gow, \& Buchanan, 2009; p.2402). Warwick et al (2009) found this behavior generally amongst undergraduate students - which applies to international undergraduates too. There are clear indications that within the online space, international students are more likely to stay in their comfort zone, acquainted websites and communities (Gomes 2015). Therefore, while people move physically all the time, they might not experience a correspondingly digital move to their new destination.

For instance, Chang et al. (2012) and Gomes (in press) reported that their international student respondents did not visit host countries' news sites but visited international ones (e.g. the British Broadcasting Corporation (BBC), Cable News Network (CNN), and other news sites from their home countries). International students from Gomes' (in press) study have known CNN and BBC from their home countries and would turn to them while in the host countries more so than to nationally-based news sites from their host countries. Further, Gomes' (2015) respondents provided different reasons for not listening to or reading news from host countries' news sites. These included disinterest in the politics and news of the host country unless the news featured issues which directly affected them (e.g. changes in permanent migration policies); an inability to identify with the issues affecting the host society; and an inability to identify with the ways in which English or their ethnic cultural languages were spoken in the host country The research also points to an online behaviour that relies on sources international students are already familiar with rather than new ones in the host country.

\section{Understanding Online Social Media and Connectedness}

In recent years there has been interest in the area of mobility and connectivity (Hjorth \& Arnold, 2012). Social media platforms include blogs, business networks, enterprise social networks, forums, microblogs, photo sharing, products/services review, social gaming, social networks, video sharing and virtual worlds (Aichner \& Jacob 2015).

Social media plays an important role for international students. Work in the area of migration often points to new permanent and temporary migrants creating links to or participating in existing networks. These networks link international students to their home countries and cultures through new advances in communication technology, such as social media and Skype. Such advances allow them to keep in touch with family and friends in the home country (Hjorth 2011; Wong 2014). Gomes et al.'s 
(2014, p. 13) study on international students in Australia recognized the importance of social media as a form of connectedness between migrant and host country:

The use of social media to stay in contact with friends and family from the home nation may assist students with forming imaginary bonds with their homelands. Doing so provides international students with virtual home-based support networks, which then allow them the opportunity to pursue and form local social networks with students other than those who come from their countries of birth.

In addition, a number of studies indicated that international students have shown a strong inclination to build online communities with their peers in the home countries through social media (Binsahl et al., 2015; Chen \& Yang, 2015; Li \& Gasser, 2005; Lin, Peng, Kim, Kim, \& LaRose, 2012) as previously indicated; the resulting translocal phenomenon is now well recognised (Martin \& Rizvi, 2014).

In summary, netizens are more likely to rely on a pre-existing set of online information sources and social networks. Together, these sources and networks make up what we term 'a digital bundle of information sources' that individuals have come to rely on. This digital bundle of information sources only includes the sources that a person relies on time and time again and does not include occasional visits a new site. It is important to note that a person's bundle of information sources can already be quite diverse and international. At the same time, others might have bundles that are limited to websites and apps based on their home country.

This means that when international students move across national borders for a period of time, they do not automatically make the digital move to new sources of information. Indeed, some studies have shown that because there are no borders online, many international students do not always make a corresponding digital move and continue to rely on previously established bundles of information sources (Chang et al, 2012). In order to better understand the phenomenon, we introduce the concept of the 'Digital Journeys' to explain how and why international students might or might not move digitally when they move physically across borders.

\section{DIGITAL JOURNEYS}

The term "journey" suggests an act of travelling from one place to another (Pearsall, 2001, p. 764). In this paper, a Digital Journey refers to the transition that an individual makes online from relying on one digital bundle of sources to the other new bundle, perhaps based on the new host country or internationally. Therefore, a Digital Journey is deemed to have been made 
when an international student starts to rely on a new digital bundle of sources that is distinct from any pre-existing ones. Digital Journeys represent the acts of moving to-and-from old and new digital bundles of sources. It is arguable that where an international student continues to rely heavily on pre-existing digital bundles of sources while experiencing the new host country, they are in effect, the translocals that Martin \& Rizvi (2014) describe. On the other hand, it may also be possible for international students to make the full digital journey and abandon their pre-existing digital bundles of sources by relying only on what the new host country has to offer.

In exploring the concept of Digital Journeys, we position the international student as the central figure. The journey that the international student makes are the online choices that they make and their motivations for those choices. Hence, there are two key aspects of the Digital Journey: a) the internal factors of the sojourner, which motivate or drive the international student to embark on a Digital Journey, and b) the factors that enhance the journey, which includes new online sites' usability and convenience, devices, and other online netizens. This is similar to Esfahani \& Chang's (2012) conceptual framework which showed there are external, internal and cognitive factors that drive the information seeking behaviors of international students. However, they did not explore the likelihood of students making the transition to new sites. The following sections explore the factors impacting on the digital journeys of international students.

\section{Internal Factors Driving the Digital Journey: Self-Identity, Collective- Identity and Skills}

Self-identity is an important determinant of where an international student might go for information. For example, Cotê and Levine (2002) described a typology for how individuals' identity formation strategies impact on the way they might interact socially. Therefore, in the case of the international student, the self-identity of the international student is an important determinant as to the extent to which they might start to rely on different online sources. Questions that might arise here are: Do the international students tend to rely on others for support and therefore follow what their peers do? Do the sojourners think they are preserving their cultural identity, or do they see themselves as adventurers? Do they see themselves as followers or leaders when exploring new and unfamiliar territory?

In addition, because the Internet is a social space, it is proposed here that a useful perspective to take when examining how Digital Journeys are made, is to look at social identity theory (Tajfel \& Turner, 1979). Social identity theory posits that an individual's perception of the self goes beyond themselves, and includes widening the social circles to which they belong. 
For example, He, Li, and Harris (2012) found that it was useful to look at brand loyalty from a social identity perspective. This is further confirmed by Wang, Yeh, and Yen (2015) who looked at how concepts related to selfidentity can impact on brand loyalty to particular online sites or social networking sites.

Communities play an important role in the online space. The collective-identity, as experienced by the international students can also impact on how far they might travel online. Online collective identities are closely related to both the online communities that sojourners belong to, which includes other like-minded individuals. Zhou's (2011) work showed the importance of social connections and processes in determining online community participation. If there is a similar community in the host country, individuals are more likely to connect with like-minded people in the local network. Some examples could include: gamers, LGBTIQ, pet owners, independent music, sports, or political affiliations. Belonging is an important part of the self-perceived identity. Do the international students feel that they belong to a particular community and does that community exist in the host country?

In summary, the concepts in self-identity and collective-identity have been shown to have an impact on the Internet sources and online behaviors of individuals in numerous contexts (ranging from health to business, and the community sector). These related self-concepts can impact on the extent to which international students will continue to rely on preexisting information bundles or start to rely on new information sources in host countries. These findings are relevant for learnings in the international education space where institutions are seeking to build new communities and change online behaviors and sources of information for new international students.

Furthermore, when an international student wants to make the transition, it is important to acknowledge if they have the skills to make the journey. One of the proposed key determinants regarding whether international students might start the digital journey lies in the digital skills and literacy of the international student themselves. Esfahani and Chang (2012) pointed out that a number of studies have shown the importance of the international students' digital skills in determining their information seeking strategies. In addition, based on ACRL Standards Committee's (1989) definition, Connaway, Lanclos and Hood (2013b) indicated that digital and information literacy refer to the ability of students to recognize and successfully seek out and evaluate the needed information. It is important to recognize that upcoming international students have a range of digital and information literacy skills, ranging from highly advanced to basic, depending on the education systems they have come from. Therefore, 
the ability of the international student to make the initial step of the journey requires some attention.

\section{Factors that Enhance the Digital Journey: User Experience, Communities and Devices}

Like a real physical journey, international students will meet people and have new experiences in their new host country. This can range from the first host country representatives they meet (before or after they arrive), to the people they interact with on a daily basis, and their fellow travelers (if any) along the journey. For example, just like the reception one gets entering a new country, first impressions are also important for digital travelers. In the online space, the new experience refers to new websites, apps and communities; the new people they meet in the new online environment become representatives of those new sites. Therefore a number of questions arise: How user friendly is host country sites for new users from different countries, cultures, or languages? Are there trusted and reliable digital guides (similar to tour guides or travel advisors), who can help the international student through the new journey in unfamiliar online territory?

An international student's introduction to a new site is something that many who study User Experience (UX) are concerned about. UX refers to the experience of the user with the system they are interacting with, including how they feel and their perception of the websites or apps (Law, Roto, Hassenzahl, Vermeeren, \& Kort, 2009). Lallemand, Gronier, and Koenig (2015) pointed out that researchers and practitioners agree on the importance of UX for design but there is no international consensus on how to define it clearly across cultures and countries because of the subjective nature of UX. However, not considering UX at all, is the surest way of turning off potential users. Therefore the ability of new sites to provide a positive experience for the newly arriving international student becomes important. One only has to look at a range of websites of China, Japan, Australia, India, and Saudi Arabia to note very quickly that they look and feel very different. For instance, their aesthetic and tone, the way they are laid out and available navigation tools are nationally unique. Hence, it is not surprising that groups of international students have very different digital experiences. If students go to a new host country with very different looking websites and apps, the information provider needs to consider and acknowledge this. Otherwise, students will be more likely to go back to their established bundles of information sources.

It is difficult, if not impossible to completely redesign the websites and apps of hosting countries to meet the diverse needs and expectations of international students. The purpose of this section is not to suggest this as a strategy but to indicate the differences that exist in the online environment. 
There are two possible strategies for dealing with the complexity of providing a positive UX for international students: (a) designing for usability, and (a) providing good transition strategies for international students in a new online environment.

Research on website users have indicated that there are a number of factors that keep netizens loyal to the websites they regularly visit. These factors include usability of the sites, which impact on netizens' trust and satisfaction, thereby increasing their loyalty to a site (Flavian, Guinalíu, \& Gurrea, 2006). Clearly, trust in and satisfaction with new sites are important for ensuring that the Digital Journey is sustained. More recently, Nusair, Bilgihan, Okumus, and Cobanoglu (2013) found that usability also has an impact on both the affective and calculative commitment of Gen Y netizens to social networking sites. This means that having websites that appeal to international students is important to create not only trust and satisfaction, but also help form emotional attachments to new sites. This action could have a positive pay-off if students have the perception that they are getting something out of using the website. In short, at the very core of this strategy, international students should be able to find the information they need easily and quickly, with relevant and helpful results.

In addition, getting information quickly is one of the important reasons why people reply on the Internet. Researchers have shown time and again that people tend to do what is most convenient and possibly quickest according to their established information seeking behaviors (Connaway et al., 2013a; Warwick et al., 2009). This means that the more an international student is looking for convenience and comfort, the less likely they might make the digital journey. If making the journey includes understanding websites in another language, there might be further impediments. Physical journeys are the same--- people look for ways to create their comfort zones when experiencing culture shock. Digitally, these comfort zones are much easier to create through social media, than offline, which means that it is much easy to go back to old online habits.

In addition, Guifoyle (2006) pointed out the importance of good orientation and transition programs for new international students. Most of the work on transition point to the need for programs that help international students adjust to and become familiar with the new physical environment of their host country. These works tend to make no reference to the digital environment. It is suggested here that good digital transition strategies have to be in place, to introduce international students to their new online environment. Such digital transition strategies should be supported by welltrained hosts (digital or otherwise) who can guide new international students in the online space. Therefore, this paper argued that in considering the Digital Journeys of international students, the digital transition is equally important. We proposed the importance of having good digital hosts/guides 
to facilitate an introduction to the new online environment in a user-friendly way. For example, orientation and transition programs at institutions might include briefing sessions on new digital sources, and mentors who can take new students through local sources of information. This might eventually be supported by an online community (as discussed below). As making a first impression is important (much like when one visits a new country), the role of the host is essential in helping with the digital transition.

Therefore, communities play a vital role in facilitating engagement with new sites. This is also potentially connected to the collective-identity of the international student. Therefore, it is important to consider if the international student might have fellow travelers along the journey. Chang et al. (2012) found that an international students' online social network influences the type of information sources the student relied on. If an online community has embraced new and diverse information sources, members of that network also tend to benefit from the variety of information. However, if an international student belongs to an online community that only uses mostly home country sites, this student is likely to rely on the sources as social network. It is unclear if this is because students only actively build social networks with other like-minded students and display similar online behaviors. Nevertheless, it points to the importance of the online networks to international students. This is where the new the international student's new network is absolutely important. When international students international student have a mix of home and host country friends, they are more likely to make the Digital Journey than those who do not (Chang et al, 2012; Gomes et al, 2015). The question here arises as to whether there are new opportunities for new online networks of communities that can continue to support international students who are making a transition. Finally, Connaway, Lanclos and Hood et al. (2013a) also suggested that it is important to understand the devices that students might choose to use or have been using. If the digital journey includes a shift in the use of different devices (Smartphones, tablets, laptops), this might bring additional barriers. For example, if an international student comes from an environment where they are used to mostly accessing their information on a smartphone, are the websites in the host country mobile friendly?

In summary, the initiation and sustaining of the Digital Journey requires some attention in both research and practice in order to fully understand the impact of the international student's previous digital experience on their ability to make any required digital transitions. The concept of Digital Journeys helps to explain comprehensively/holistically why international students often do not seem to rely on new information sources and are misinformed. This concept also explores the online experiences of international students as they move between countries and 
challenges the notion that all students will use new information sources when they do so.

\section{DISCUSSION AND CONCLUSIONS}

Research into the digital experiences of international students is relatively recent given the widespread use of social media. Much of the work in this field focused on what international students use social media for as well as the benefits of social media for the students (Li \& Gasser, 2005; Lin et al., 2012; Olding, 2013; Rahman, 2014). Much has been discussed that social media plays a vital role in on facilitating social connections among different groups of peers. However, much of the research on international students has been limited to their cross-cultural experiences and not necessarily included their digital experiences (McFaul, 2016; Yan \& Sendall, 2016). The digital experience is a new consideration and much less researched. This article hopes to address some of that deficiency by pointing to new directions for research in this area.

One area of work on the digital experiences of international students which has received some well warranted attention is the successful use of social media and other online tools in supporting the learning and intercultural interactions of international students (Arkoudis et al., 2010; Cowling \& Novak, 2012; Gray, Chang \& Kennedy, 2010; Shao \& Crook, 2015). These reports are based on case studies within the curriculum. They are often characterized by clear scaffolding and guidelines within the curriculum to help the student learner transition into a new online learning space. They are often also supported by well thought out usable and trustworthy sources of information and infrastructure.. In various ways, these studies acknowledged the importance of user experiences, good digital transition strategies, learning opportunities, considerations for the devices used by students, and also support through the online learning community.

Despite the external factors stated above, research in this field also pointed to the importance of acknowledging the internal needs of the students (Zhao \& McDougall, 2008). Therefore, while not explicitly talking about the concept of Digital Journeys, success in the use of social networking sites within curricular has shown that online models of education need to factor in the international students' needs. This is necessary to help facilitate adoption of new teaching methodologies. Carefully engineered and scaffolded sustained use of these social networking sites could lead to successful learning outcomes.

Institutions and service providers catering to international students need to realize that the contemporary international student is not only coping with new or different physical environments encountered when they move between countries but digital ones too. International students are not only 
adapting to a new country, a new culture, a new society, a new learning system and sometimes to an unfamiliar or not well used language, but also to a new digital environment. However, the digital environment is the one area in which an international student has the most control over because they can choose to ignore any new digital spaces in favor of pre-existing ones. Indeed, the current research on the social networks and information sources of international students has indicated that students are choosing to ignore new digital environments in favor of familiar ones from home (Chang et al, 2012; Gomes, 2014) as well as using social media to support existing networks with friends from home cultures (Hodis \& Hodis, 2012; Lee et al., 2011;). Institutions and international student service providers need to consider the digital journeys of international students when making information available to them.

This conceptual paper brought together related research in the fields of information seeking behaviors, social media and the experiences of international students. The concept needs to be mapped out and empirically tested in more detail and in stages. Therefore, future work is needed to understand better the different aspects of Digital Journeys.

\section{CONCLUSION}

Digital journeys are expeditions that individuals may or may not undertake as they sojourn across physical borders. In the case of international students, this represents their use and reliance on different sources of online information. The physical journey certainly does not result in the international students leaving their pre-existing bundle of information sources of their country of origin. Rather, international students may bring this bundle with them. Therefore, each student balances different digital environments which may well be as culturally diverse as their physical environments. Thus, they may be challenged by their new digital environment and not be able to adapt well. Hence they may not be able to or know how to access the bundle of information sources available to them. Moreover, maintaining connections to the home country's digital environment means that they need to stay up to date with the information sources they are used to. The result is an international student who juggles sometimes very different digital cultures.

\section{REFERENCES}

Abrahamse, A., Johnson, M., Levinson, N., Medsker, L., Pearce, J. M., Quiroga, C., \& Scipione, R. (2015). A virtual educational exchange: A North-South virtually shared class on sustainable development. Journal of Studies in International Education. 19 (2), 140-159. 
ACRL Standards Committee. (1989). Information iteracy Competency Standards for Higher

Education. ACRL Association of College \& Research Libraries. Retrieved from http://www.ala.org/acrl/standards/informationliteracycompetency.

Aichner, T., \& Jacob, F. (2015). Measuring the degree of corporate social media use. International Journal of Market Research. 57(2), 257-75. Retrieved from https://www.mrs.org.uk/ijmr_article/article/104155

Alzougool, B., Chang, S., Gomes, C., \& Berry, M. (2013). Finding their way around: International students' use of information sources. Journal of Advanced Management Science. 1(1), 43-49. doi: 10.12720/joams.1.1.43-49

Alzougool, B., Chang, S., \& Gray, K. (2013). The nature and constitution of informal carers' information needs: What you don't know you need is as important as what you want to know. Information Research, 18(1). Retrieved from: http://www.informationr.net/ir/181/paper563.html.

Arkoudis, S. A., Yu, X. Y., Baik, C. W. B., Chang, S., Lang, I. W. L., Lang, J., Pearce, A., \& Watty, K.W. (2010). Finding Common Ground: enhancing interaction between domestic and international students. Guide for academics. Report for Australian Learning \& Teaching Council. Sydney, Australia: Australian Learning and Teaching Research Council: Studio Teaching Project.

Australian Department of Education and Training. (2015) International education in Australia, 1994-2015, Department of Education and Training Media Centre. Retrieved from: https://internationaleducation.gov.au/research/International-StudentData/Pages/InternationalStudentData2015.aspx

Binsahl, H., Chang, S., \& Bosua, R. (2015). Identity and belonging: Saudi female international students and their use of social networking sites. Crossings: Journal of Migration \& Culture, 6(1), 81-102. doi: 81-102. doi: 10.1386/cjmc.6.1.81_1.

Bista, K., \& Foster, C. (2016). Global perspectives and local challenges surrounding international student mobility. Hershey, PA: IGI Global.

Chang, S., Alzougool, B., Berry, M., Gomes, C., Smith, S., \& Reeders, D. (2012). International students in the digital age: Do you know where your students go to for information? Proceedings of the Australian International Education Conference.

Chen, L., \& Yang, X. (2015). Nature and effectiveness of online social support for intercultural adaptation of Mainland Chinese international students. International Journal of Communication, 9, 2161-2181.

Church, K., Smyth, B., Bradley, K., \& Cotter, P. (2008). A large scale study of European mobile search behaviour. Proceedings of the $10^{\text {th }}$ MobileHCI (International conference on Human computer interaction with mobile devices and services).

Connaway, L. S., Lanclos, D. M., \& Hood, E. M. (2013a). I always stick with the first thing that comes up on Google: Where People Go for Information, What They Use, and Why. Educause Review Online. Retrieved from http://www.educause.edu/ero/article/ialways-stick-first-thing-comes-google-where-people-go-information-what-they-useand-why.

Connaway, L.S., Lanclos, D. M., \& Hood, E. M. (2013b). I find Google a lot easier than going to the library website: Imagine Ways to Innovate and Inspire Students to Use the Academic Library. Proceedings of the Association of College \& Research Libraries (ACRL) 2013 conference, April 10-13, Indianapolis, IN.

Cotê, J. E., \& Levine, C. (2002). Identity Formation, Agency, and Culture. Mahwah, N. J.; London: Lawrence Erlbaum Associates.

Cowling, M., \& Novak, J. (2012). The implementation of social networking as a tool for improving student participation in the classroom, Proceedings of the 2011 ISANA International Education Association Conference, Tasmania. Hobart. Retrieved from http://www.proceedings.com.au/isana/docs/2011/paper_Novak_Cowling.pdf

Esfahani, L., \& Chang, S. (2012). Factors impacting information seeking behaviour of international students: Towards a conceptual model, Proceedings of the 2012 ISANA 
International Education Association Conference, Tasmania. Retrieved from http://isana.proceedings.com.au/docs/2012/isana2012Final00044.pdf.

Flavian, C., Guinalíu, M., \& Gurrea, R. (2006).The role played by perceived usability, satisfaction and consumer trust on website loyalty. Information \& Management, 43 (1), 1-14. doi: http://dx.doi.org/10.1016/j.im.2005.01.002

Freyne, J., Berkovsky, S., Daly, E. M., \& Geyer, W. (2010). Social networking feeds: recommending items of interest. Proceedings of the $4^{\text {th }}$ ACM Conference on Recommender Systems. 277-280.

Gomes, C. (2014). Xenophobia online: unmasking Singaporean attitudes towards 'foreign Talent' migrants. Asian Ethnicities. 15(1), 21-40. doi: http://dx.doi.org/10.1080/14631369.2013.784511

Gomes, C. (2015). Negotiating everyday life in Australia: unpacking the parallel society inhabited by Asian international students through their social networks and entertainment media use. Journal of Youth Studies, 18(4), 515 - 536. doi: http://dx.doi.org/10.1080/13676261.2014.992316

Gomes, C. (Forthcoming) Transient Mobility and Middle Class Identity: Media and Migration in Australia and Singapore, Palgrave Macmillan.

Gomes, C., Berry, M., Alzougool, B., \& Chang, S. (2014). Home Away From Home: International Students and their Identity-Based Social Networks in Australia. Journal of International Students, 4(1), 2-15.

Gray, K., Chang S., \& Kennedy, G. (2010). Use of social web technologies by international and domestic undergraduate students: Implications for internationalising learning and teaching in Australian universities. Technology, Pedagogy and Education, 19(1), 31-46. doi: http://dx.doi.org/10.1080/14759390903579208

He, H., Li, Y., \& Harris, L. (2012). Social identity perspective on brand loyalty, Journal of Business Research, 65(5), 648-657. doi: Social identity perspective on brand loyalty.

Hechanova-Alampay, R., Beehr, T. A., Christiansen, N. D., Van Horn, R. K. (2002). Adjustment and strain among domestic and international student sojourners: A longitudinal study. School Psychology International, 23(4), 458-474. doi: doi: $10.1177 / 0143034302234007$

Hodis, G. M., \& Hodis, F. A. (2012). A mediation analysis of international students' patterns of computer-mediated communication. International Journal of Communication, 6, 2846-2869.

Hjorth, L. (2011). Still mobile: Cross-generational SNS usage in Shanghai. In Wilken, R. and Goggin, G. (Eds.), Mobile Technologies and Place (pp.140-156). London \& New York: Routledge.

Hjorth, L., \& Arnold, M. (2012). Online@AsiaPacific: Networked sociality, creativity and politics in the Asia-Pacific region. Routledge, New York.

Khawaja, N.G. \& Dempsey, J. (2008). A comparison of international and domestic teriary students in Australia. Australian Journal of Guidance and Counselling, 18 (1), 30-46. doi: http://dx.doi.org/10.1375/ajgc.18.1.30

Lallemand, C., Gronier, G., \& Koenig, v. (2015). User experience: A concept without consensus? Exploring practitioners' perspectives through an international survey, Computers in Human Behavior, 4, 35-48. doi: http://dx.doi.org/10.1016/j.chb.2014.10.048

Law, E., Roto, V., Hassenzahl, M., Vermeeren, A., \& Kort, J. (2009). Understanding, scoping and defining user experience: A survey approach. Proceedings of Human Factors in Computing Systems conference. CHI'09. Boston, MA, USA. doi: 10.1145/1518701.1518813

Lee, E.J., Lee, L., \& Jang, J. (2011). Internet for the internationals: effects of internet use motivations on international students' college adjustment. Cyber Psychology, Behavior \& Social Networking,14(7/8), 433-437. doi: 10.1089/cyber.2010.0406. 
Leask, B. (2009). Using formal and informal curricula to improve interactions between home and international students. Journal of Studies in International Education., 13(2),205221. doi: $10.1177 / 1028315308329786$.

Li, A., \& Gasser, M.B. (2005). Predicting Asian international students' sociocultural adjustment: A test of two mediation models. International Journal of Intercultural Relations, 29(5), 561-576. doi: Predicting Asian international students' sociocultural adjustment: A test of two mediation models.

Lin, J.-H., Peng, W., Kim, M., Kim, S. Y., \& LaRose, R. (2012). Social networking and adjustments among international students. New Media \& Society, 14(3), 421-440. doi: $10.1177 / 1461444811418627$

Martin, F., \& Rizvi, F. (2014). Making Melbourne: Digital connectivity and international students' experience of locality. Media Culture \& Society, 36(7), 1016-1031. doi: $10.1177 / 0163443714541223$.

McFaul, S. (2016). International Students' Social Network: Network Mapping to Gage Friendship Formation and Student Engagement on Campus. Journal of International Students,. 6(1), 1-13.

Mikal, J. P., Yang, J., \& Lewis, A. (2015.) Surfing USA: How Internet Use Prior to and During Study Abroad Affects Chinese Students' Stress, Integration, and Cultural Learning While in the United States. Journal of Studies in International Education, 19, 203-224. doi:10.1177/1028315314536990.

Moody, D. L. (2005). Theoretical and practical issues in evaluating the quality of conceptual models: Current state and future directions. Data \& Knowledge Engineering, 55, 243276.

Na, J., Kosinski, M., \& Stillwell, D. J. (2015). When a new tool is introduced in different cultural contexts individualism-collectivism and social network on Facebook. Journal of Cross-Cultural Psychology, 46(3), 355-370

NetMarketshare. (2016). Desktop Web Engine Market Share, Retrieved from https://www.netmarketshare.com/search-engine-marketshare.aspx?qprid=4\&qpcustomd $=0$.

Nusair, K., Bilgihan, A., Okumus, F., \& Cobanoglu, C. (2013). Generation Y travelers' commitment to online social network websites. Tourism Management, 35, 13-22. doi: http://dx.doi.org/10.1016/j.tourman.2012.05.005

Olding, A. (2013). An investigation of the social relationships and social interactions amongst international students studying in Australia: A case study using Facebook. University of Tasmania. Retrieved from http://eprints.utas.edu.au/17111/1/FrontOlding-thesis-2013.pdf.

Pearsall, J. (Ed.) (2001). The Concise Oxford Dictionary. 10 ${ }^{\text {th }}$ Edition. Oxford \& New York: Oxford University Press.

Poyrazli, S., \& Lopez, M. D. (2007) An exploratory study of perceived discrimination and homesickness: A comparison of international students and American students. Journal of Psychology: Interdisciplinary and Applied, 141(3), 263-280.

Qiu, W. (2011). Language adjustment of international students in the US: A social network analysis on the effects of language resources, language norm and technology. (unpublished doctoral dissertation). Michigan State University, Ann Arbor. Retrieved fromhttp://ez.library.latrobe.edu.au/login?url=http://search.proquest.com/docview/8470 06575? accounid=12001.

Qiu, L., Lin, H., \& Leung, A. K. Y. (2013). Cultural differences and switching of in-group sharing behavior between an American (Facebook) and a Chinese (Renren) social networking site. Journal of Cross-Cultural Psychology, 44, 106--121. doi:10.1177/0022022111434597.

Rahman, N. (2014). The usage and online behavior of social networking sites among international students in New Zealand. The Journal of Social Media in Society, 3(2), 65-81. 
Shao, Y., \& Crook, C. (2015). The Potential of a Mobile Group Blog to Support Cultural Learning Among Overseas Students. Journal of Studies in International Education, 19(5), 399-422. doi:10.1177/1028315315574101.

Sin, S. C., \& Kim, K. S. (2013). International students' everyday life information seeking: The informational value of social networking sites. Library \& Information Science Research, 35(2), 107-116. doi: http://dx.doi.org/10.1016/j.lisr.2012.11.006

Song, Y-S. (2004). A comparative study of information-seeking behaviors of domestic and international business students. Research Strategies, 20(1), 23-34. doi: http://dx.doi.org/10.1016/j.resstr.2005.07.001

Tajfel, H., \& Turner, J. C. (1979). An integrative theory of intergroup conflict. In Austin, W.G. \& Worchel, S. (Eds.). The Social Psychology of Intergroup Relations. Monterey, CA: Brooks-Cole.

Wang, T., Yeh, R. K., \& Yen, D. C., (2015). Influence of customer identification on online usage and purchasing behaviors in social commerce. International Journal of HumanComputer Interaction, 31(11), 805-814.

Warwick, C., Rimmer, J., Blandford, A., Gow, J., \& Buchanan, G. (2009). Cognitive economy and satisficing in information seeking: A longitudinal study of undergraduate information behaviour. Journal of the American Society for Information Science and Technology, 60(12), 2402-2415. doi: 10.1002/asi.21179.

Wong, J. W. E. (2014). Media, mobility \& international student well-being. Proceedings of the 2014 ISANA International Education Association Conference, Adelaide. Retrieved from http://proceedings.com.au/isana/docs/2014/Wong_Joshua_PAPER.pdf

Yan, Z., \& Sendall, P. (2016). First year experience: How we can better assist first-year international students in higher education. Journal of International Students, 6(1), 3551.

Zhao, N., \& McDougall, D. (2008). Cultural influences on Chinese students' asynchronous online learning in a Canadian university. Journal of Distance Education, 22(2), 59-79.

Zhou, T. (2011). Understanding online community user participation: a social influence perspective. Internet Research, 21(1), 67-81. doi: http://dx.doi.org/10.1108/10662241111104884

SHANTON CHANG, $\mathrm{PhD}$, is an associate professor in Information Systems at The University of Melbourne. His research areas include online behavior, information needs, and social media, within the contexts of health, education and business. Email: shanton.chang@unimelb.edu.au

CATHERINE GOMES, $\mathrm{PhD}$, is a senior lecture in Media and Communication. Her research interests include migration and mobility, identity, and ethnic and cultural diversity.

Email: catherine.gomes@rmit.edu.au 